\title{
Interaction between Technology Innovation System and Knowledge Innovation System of Universities in Hubei Province
}

\author{
Rongyan Zhu ${ }^{1,2, a^{*}}$ Shufan Zhu ${ }^{1, b}$ and Xiaofen Zhou ${ }^{1, c}$ \\ ${ }^{1}$ College of Logistics Wuhan Technology and Business University, No. 3 Huangjiahu West Road, \\ Baishazhou Avenue, Wuhan, China 430065 \\ ${ }^{2}$ Hubei Business Service Research Development Center, No. 3 Huangjiahu West Road, \\ Baishazhou Avenue, Wuhan, China 430065 \\ a13007132492@163.com, ${ }^{\mathrm{b}}$ 307947682@qq.com, ${ }^{\mathrm{c}} 103343280 @ q q . c o m$
}

Keywords: Colleges and Universities; Technology Innovation; Knowledge Innovation

\begin{abstract}
Colleges and universities carry out technology innovation and knowledge innovation at the same time. As a large education province, Hubei Province in where the interaction between technology innovation system knowledge innovation system of colleges and universities are studied, that is of great significance to regional and national innovation system. Based on the framework analysis of the university innovation system, some indexes are selected for regression analysis according to the connotation of technology innovation and knowledge innovation. The regression results show that technology innovation system and knowledge innovation system has weak correlation in Hubei province. The interaction between those two is very complex.
\end{abstract}

\section{Introduction}

Colleges and universities are the convergence areas of various technological innovation resources, as well as one of the main bodies of knowledge innovation. They also carry two activities of scientific research and higher education, and combine them organically. In the era of market and knowledge-based economy, technological innovation can promote the benign interaction between technology and economy, which has become a bridge for the combination of those two. Knowledge innovation provides the foundation and impetus for the national innovation capability and its sustainable economic development.

Since the reform and opening up, science and technology of universities in China has developed rapidly, and become the main force of China's scientific and technological innovation. The scientific and technological innovation resources required by universities are connected with the national or regional innovation system through the university innovation system. Hubei Province is a major education province in China. By the end of May 2016, there are a total of 129 higher education institutions in Hubei, of which 68 are undergraduate universities, and 61 are higher vocational colleges. These universities include two original 985 engineering universities and seven original 211 Engineering universities. Not only is there a large number of colleges and universities in Hubei many, but the strength of those schools is also very strong. The mutual interaction between technology innovation system and knowledge innovation system of universities has formed a consensus. The research and discussion of the relationship between those two in Hubei, can be conducive to the improvement of the innovation system, and the relationship between scientific research and higher education will be more closely combined by colleges and universities in Hubei Province, which also can fully play a role in the national innovation system.

\section{Literature Review}

In the era of knowledge economy, the social and economic development depends on innovation and progress of knowledge. Under this circumstance, the function of colleges and universities has changed. They integrate teaching, scientific research and social service into a whole, not only spreading knowledge and training personnel, but also have become the main force of knowledge innovation and an important force of the national technology innovation system[1,2,3]. In addition to education and scientific research, colleges and universities integrate themselves into society which is their third mission[4]. That is to say, University Innovation more widely contributes to national or regional innovation and economic growth. Zhang Deming and Xie Baosheng[5] studied the relationship between R\&D input on universities of science, industry, agriculture and medicine and technological innovation of large and medium-sized industrial enterprises in China. S. Datta and M. Saad[6] conducted a study on the evolution of India innovation system and the role of 
universities in various innovative theoretical systems, and pointed out the path dependence problem in the more than 150 years' evolution process of Indian university system. Yin Kechun[7] believed that the intellectual property system plays an important role in the technological innovation of colleges and universities, and analyzed the problems and causes of the intellectual property protection in Chinese colleges and universities. Peng Linan[8] analyzed the realization process of knowledge and technology innovation in universities, and the demand for the construction of intellectual property information management system in China. Lavie D. and Drori I.[9] believed that the cooperation between universities and partner universities contributes to knowledge creation, and the cooperation between universities and enterprises contributes to the application of knowledge.

The innovation activities in colleges and universities are affected by many factors, such as the proportion of high-level scientific researchers participating in scientific research activities in colleges and universities, the emphasis on basic research, the number and structure of students, the closeness with enterprises, etc[10]. In order to better study the innovation system of colleges and universities, scholars have made corresponding research on the measurement and evaluation of technological innovation and knowledge innovation. Ying Xuan and Sun Jiqing[11] thought that it is biased to evaluate the scientific and technological innovation ability in universities only from the patent quantity. So it is relatively comprehensive to evaluate the innovation ability of colleges and universities from the aspects of cooperative research, the effective patent age combined with the patent quantity. Liang Yan et al.[12] established a set of evaluation index system for university science and technology innovation ability. Wu Jie[13] evaluated the knowledge innovation ability of 15 colleges and universities from 4 aspects: resource input ability, innovation tendency, scientific and technological ability and the profit index of knowledge innovation. In the process of empirical analysis of technological innovation capability of Chinese universities, Bao Zhiyan[14] uses 7 patent indicators as the evaluation basis.

The existing research on university innovation system in China focuses on its relationship with the national innovation system, its status and role in the national or regional innovation system and its spillover effects on the technological innovation of enterprises and so on. There is less research on the relationship among subsystems of innovation system in colleges and universities. On the other hand, because the main force of technology innovation system is mostly enterprise, there are more researches on the enterprise in the technological innovation system, while the research in technological innovation system in universities is less. As for the measurement and evaluation of innovation ability and innovation output in colleges and universities, there is a coincidence between technology innovation and knowledge innovation indicators in the existing research, which is also one of the reasons why the relationship between the two systems is less studied.

\section{Framework of Innovation System in Colleges and Universities}

University innovation system consists of three major systems: knowledge innovation system, technology innovation system and management innovation system, and the three systems support and motivate each other. Knowledge innovation is the process to acquire new knowledge of science and technology through basic research and applied basic research, including new theories, new methods and new scientific laws etc. which provide new ways for people to understand and transform the world. The knowledge innovation system of colleges and universities is engaged in basic research and applied basic research by experts and professors or scholars through platform such as key laboratories and research bases, to carry out various types of fund projects and basic research. The system mainly proceeds with production, diffusion and dissemination of knowledge.

Technology innovation is through the application research and technology $R \& D$, to combine scientific research in colleges and universities closely with the development of society and economy, to promote the transformation of scientific and technological achievements in accordance with the needs of social and economic development, to improve the national or regional competitiveness, to promote social and economic growth. The technology innovation system of colleges and universities is to integrate resources and elements of colleges and universities with social resources by the experts, scholars and the advisory institutions in colleges and universities, to carry out the development of various new products and industries, the promotion and implementation of the research results, to promote the creation, innovation, learning and communication of new technologies.

The management innovation system of colleges and universities is the related administrative organization in teaching and scientific research. Through institutional reform and innovation policy, the system optimally allocates the innovation resources on the market oriented basis, to ensure the normal operation of university 
knowledge innovation and technology innovation system, so that to keep colleges and universities on developing as well as to promote sustainable economic development.

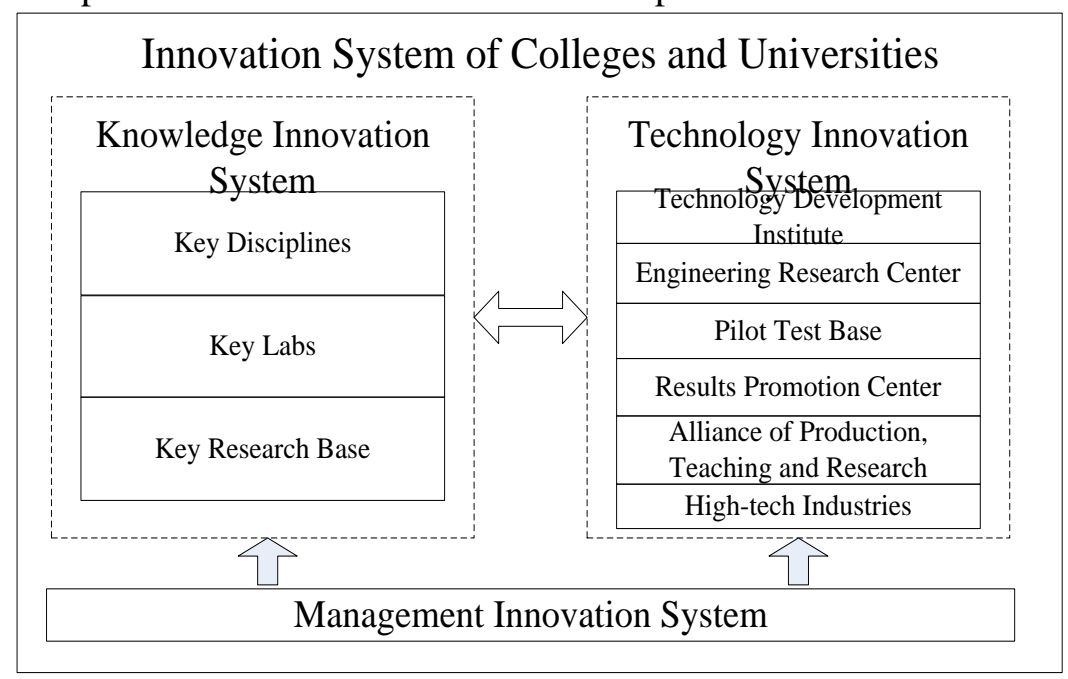

Figure 1. framework diagram of University Innovation System

Colleges and universities are the main executive body of knowledge innovation system, and also one of the main executive bodies of technology innovation system. Knowledge innovation in colleges and universities provides the foundation and inspiration source for technology innovation activities. Technology innovation guides the development direction of knowledge innovation activities, while the management innovation provides operational guarantee for the two major systems. The framework of the innovation system in colleges and universities is illustrated in Fig. 1.

\section{Model Indicators Selection and Data Sources}

Indicators Selection. In order to explore the relationship between the knowledge innovation system and technology innovation system of colleges and universities in Hubei province, select the indicators that can represent the knowledge innovation ability and technology innovation capacity. That is, select and analyze those indicators of knowledge innovation output capacity and technology innovation output capacity. Able to reflect the innovation ability of colleges and universities is mainly some achievements of scientific research, including research papers and works, scientific research awards, graduate students, patents and other achievements. Knowledge innovation output capability indicators should be able to reflect the original innovation ability of colleges and universities, while technology innovation output capacity indicators should be able to reflect the transformation ability of scientific research achievements in colleges and universities. Therefore, choosing the number of high level papers published (HLPP), the number of scientific research awards (SRA) and the number of invention patents authorization (IPA) as a measure of knowledge innovation output capacity, selecting the income from the transfer of scientific and technological achievements as a measure of technology innovation output capacity, including the real income of technology transfer (RITT) and patent sales (RIPS).

Data sources and model building. All the data used in this paper are derived from "Scientific and Technical Statistics Compilation of Higher Education Institutions" in China from 2007 to 2016. Considering that the number of the high level papers published mainly refers three major indexed published papers, since there is no such statistics in the compilation, the number of papers published in foreign and national academic journals (PPFNAJ) is used to instead of the indicator. The number of scientific research awards is the sum of the National Natural Science Award, the National Technology Invention Award, National Science and Technology Progress Award, the Science and Technology Progress Award of State Council Departments and the Provincial Science and Technology Progress Award. Thus, the original data of knowledge innovation and technology innovation output Hubei province from 2006 to 2015 are shown in Table 1. 
Table 1 2006-2015 raw data of innovation out indicators in Hubei Province

\begin{tabular}{|l|l|l|l|l|l|}
\hline Years & PPFNAJ[Articles] & SRA[items] & IPA[items] & RIPS[1K RMB] & RITT[1K RMB] \\
\hline 2006 & 7418 & 270 & 423 & 11533 & 76155 \\
\hline 2007 & 8178 & 333 & 480 & 7290 & 46181 \\
\hline 2008 & 11103 & 328 & 604 & 5775 & 23246 \\
\hline 2009 & 10944 & 312 & 730 & 13167 & 38025 \\
\hline 2010 & 13712 & 272 & 883 & 13680 & 35900 \\
\hline 2011 & 16877 & 314 & 1153 & 16437 & 45680 \\
\hline 2012 & 15667 & 321 & 1573 & 46451 & 66142 \\
\hline 2013 & 14704 & 295 & 1467 & 22667 & 48416 \\
\hline 2014 & 18710 & 313 & 1708 & 8452 & 36447 \\
\hline 2015 & 19217 & 315 & 830 & 29691 & 88623 \\
\hline
\end{tabular}

The classic Griliches-Jaffe knowledge production function is chosen to analyze the problem. Under the framework of this model, the output of knowledge innovation is linear with the output of technology innovation, or can be interpreted as that the output of knowledge innovation is the input of technology innovation and will affect the output of technology innovation. Then the production function model of knowledge innovation and technology innovation in colleges and universities can be expressed as Eq. 1.

$\mathrm{TI}=\mathrm{f}(P N, R N, \mathrm{AP})$

In which, TI means the real income of technology transfer or the real income of patent sales; PN is the number of papers published in foreign and national academic journals; $\mathrm{RN}$ is the number of scientific research awards; AP is the number of invention patents authorization. Regression of the Eq. 1's logarithmic form yields Eq. 2.

$$
\operatorname{lnTI} t=\delta+\alpha \ln P N_{t-k}+\beta \ln R N_{t-k}+\gamma \ln A P_{t-k}+\varepsilon
$$

In the Eq. $2, \delta$ is a constant; $\alpha, \beta, \gamma$ are the output elasticity of the explanatory variable; $t$ represents time; considering the periodicity of knowledge innovation to technology innovation, the $\mathrm{K}$ represents the lag period of the transformation from knowledge innovation to technology innovation; and $\varepsilon$ represents the error.

\section{Model Solution and Result Analysis}

The real income of patent sales and technology transfer are regressed respectively. Taking into account the lag problems, the model chooses the optimal regression fitting under different lag periods as the result. The regression results are shown in table 2.

Table 2 Regression Analysis of knowledge innovation ability and technology innovation ability

\begin{tabular}{|l|c|c|c|c|c|c|c|}
\hline \multirow{3}{*}{ RIPS } & $\delta$ & $\alpha$ & $\beta$ & $\gamma$ & $\mathrm{R}^{2}$ & $\mathrm{~F}$ & Sig. \\
\cline { 2 - 8 } & -20.297 & $\begin{array}{c}4.031 \\
(0.85) * *\end{array}$ & $\begin{array}{c}0.348 \\
(0.033)\end{array}$ & $\begin{array}{c}-1.489 \\
(0.733) *\end{array}$ & 0.809 & 7.055 & 0.03 \\
\hline \multirow{3}{*}{ RITT } & $\delta$ & $\alpha$ & $\beta$ & $\gamma$ & $\mathrm{R}^{2}$ & $\mathrm{~F}$ & Sig. \\
\cline { 2 - 8 } & 7.385 & $\begin{array}{c}1.549 \\
(0.7) *\end{array}$ & $\begin{array}{c}-1.467 \\
(-0.15)\end{array}$ & $\begin{array}{c}-0.426 \\
(0.567)\end{array}$ & 0.606 & 2.565 & 0.168 \\
\hline
\end{tabular}

Note: the data in parentheses are single factor correlation coefficients; $* *$ and $*$ indicate that the $\mathrm{t}$-test passed the significant levels of $5 \%$ and $10 \%$ respectively.

To some extent, knowledge innovation output and technology innovation output can reflect results of each system operation. It can be seen from table 2 that the interaction between knowledge innovation system and technology innovation system of colleges and universities in Hubei. For the real income of patent sales in Hubei Province, the indicator is significant linear with knowledge innovation. But the output elasticity of the indicator with the number of invention patents authorization is -1.489 , and the single factor correlation between those two indicators is high, which indicates that the increase in the number of invention patents authorization in colleges and universities has played a certain restraining effect on the sale of patents in 
Hubei at present. The result is unexpectedly beyond common sense. However, after thinking deeply, it will be found that the allocation of innovation resources in knowledge innovation and technology innovation will affect the output, mainly due to the limited innovation input resources of colleges and universities. Under normal circumstances, teachers in colleges and universities are engaged in knowledge innovation and technology innovation at the same time, while the investment of funds, time and energy is limited, the innovation input resources tend to one side, then the development of the other will inevitably be affected to some extent. On the other hand, the existing teacher promotion system focuses on the knowledge innovation activities such as paper publication and patent declaration etc. It shows that the innovation management system and mechanism of colleges and universities in Hubei need to be improved so as to ensure the coordinated development of knowledge innovation system and technology innovation system. An important resource of knowledge innovation and technology innovation activities in colleges and universities is the human resources, that are the workers engaged in creative activities, whose enthusiasm and initiative in the innovation activities is influenced by the innovation management system and management mechanism.

For the actual income of technology transfer, the regression model is not very significant, but the coefficient of determination is 0.606 , which indicates that the regression equation has a certain degree of interpretation to the actual income of technology transfer. The output elasticity of the actual income of technology transfer with scientific research awards and the invention patent authorization are negative, which shows that the indicators restrain each other. The result shows once again that higher education institutions need to coordinate and allocate the innovation resources invested in terms of manpower, capital and other forms. The innovation system of colleges and universities in Hubei Province needs further improvement. It also reflects the general consensus in China that technology innovation is mainly the work of enterprises. In general, knowledge innovation system and technology innovation system of colleges and universities in Hubei has weak correlation currently. Although the results reflect the interaction and the mutual promotion between the two systems, there are also mutual inhibition factors within the system.

\section{Conclusion}

The innovation system of colleges and universities plays an important role in the innovation system of the country or region, and the system mainly includes knowledge innovation system, technology innovation system and innovation management system. These three subsystem complement each other. In order to explore the relationship between knowledge innovation system and technology innovation system of colleges and universities, the paper selects a number of indicators that reflect the ability of knowledge and technology innovation, based on the data from 2006 to 2015 in Hubei, to conduct regression analysis. The results show that there is a complicated interactive relationship between knowledge innovation system and technology innovation system of colleges and universities in Hubei. The paper only conducts the regression analysis from several major indicators. In the future, it is necessary to carry out further studies from more aspects and more indicators, to explore the underlying causes for the weak correlation between the knowledge innovation system and the technology innovation system of colleges and universities in Hubei.

\section{Acknowledgements}

The authors gratefully acknowledge the editor and referees for their work and valuable comments. This research is partially supported by the 2016 Year Open Fund Project of Hubei Business Service Research Development Center, the 2014 Year Wuhan Technology and Business University the Second Round Research Project of Doctoral Fund (grant number D2014006).

\section{References}

[1] Wei Yang, Collegs and universities become the important force of national technological innovation system, China Education Daily. 2012-6-18.

[2] Xiaojun You, Debin Du, Binfeng Zhang, Heng Li, The assessment of the role of universities within national knowledge-based innovation system based on the comparative study of selected innovative countries and China, Science and Technology Innovation Herald.35 (2014) 89-97.

[3] Gunasekanra C, Reframing the role of universities in the development of regional innovation systems, Science and Public Policy. 33 (2006) 137-150.

[4] Piirainen K A, Tanner A N, Alkærsig L, Regional foresight and dynamics of smart specialization: A typology of regional diversification patterns, Technological Forecasting and Social Change. 115 (2017) 
289-300.

[5] Deming Zhang, Baosheng Xie, Analysis on knowledge spillover of R\&D investment in universities of technology agriculture and medicine on enterprise technical innovation, Science Research Management. 35 (2014) 136-143.

[6] Surja Datta, Mohammed Saad, University and innovation systems: the case of India, Science and Public Policy. 38 (2011) 7-17.

[7] Kechun Yin, Research on university technology innovation and intellectual property protection, Co-Operative Economy \& Science. 7 (2016) 186-188.

[8] Linan Peng, Construction of intellectual property information management system in university knowledge and technology innovation, Seeking Truth. 39 (2012) 65-68.

[9] Lavie D, Drori I, Collaborating for knowledge creation and application: the case of nanotechnology research programs, Organization Science. 23 (2012) 704-724.

[10] Xibao Li, Feng Xie, An empirical study of research productivity in Chinese universities, 1 (2013) 39-53.

[11] Xuan Ying, Jiqing Sun, Research of high-tech innovation based on patent data analysis, Journal of Modern Information. 31 (2011) 165-168.

[12] Yan Liang, Yuwei Lin, Xiangyin Li, University science and technology innovation capability evaluation index system, Technology and Innovation Management. 31 (2010) 377-380.

[13] Jie Wu, Comprehensive evaluation of university knowledge innovation capability based on entropy method, Journal of Industrial Technological Economics. 26 (2007) 53-55.

[14] Zhiyan Bao, Empirical study on technical innovation ability of universities based on patent information measure and analysis, Journal of Library and Information Sciences in Agriculture. 28 (2016) 5-10. 